\title{
GCU
}

Glasgow Caledonian

University

University for the Common Good

\section{Are the attitudes of exercise instructors who work with older adults influenced by training and personal characteristics?}

Hawley, Helen; Skelton, Dawn; Campbell, Malcolm; Todd, Chris

Published in:

Journal of Aging and Physical Activity

Publication date:

2012

Document Version

Publisher's PDF, also known as Version of record

Link to publication in ResearchOnline

Citation for published version (Harvard):

Hawley, H, Skelton, D, Campbell, M \& Todd, C 2012, 'Are the attitudes of exercise instructors who work with older adults influenced by training and personal characteristics?', Journal of Aging and Physical Activity, vol. 20, pp. 47-63. <http://journals.humankinetics.com/japa-back-issues/japa-volume-20-issue-1-january/are-theattitudes-of-exercise-instructors-who-work-with-older-adults-influenced-by-training-and-personal-characteristics>

\section{General rights}

Copyright and moral rights for the publications made accessible in the public portal are retained by the authors and/or other copyright owners and it is a condition of accessing publications that users recognise and abide by the legal requirements associated with these rights.

Take down policy

If you believe that this document breaches copyright please view our takedown policy at https://edshare.gcu.ac.uk/id/eprint/5179 for details of how to contact us. 


\title{
Are the Attitudes of Exercise Instructors Who Work With Older Adults Influenced by Training and Personal Characteristics?
}

\author{
Helen Hawley, Dawn A. Skelton, Malcolm Campbell, \\ and Chris Todd
}

\begin{abstract}
Little is known about the relationship between attitudes and characteristics of instructors and uptake and adherence of older people to exercise classes. This article explores these issues. Methods: The authors surveyed 731 UK exercise instructors with specialist older adult exercise qualifications. A questionnaire investigated instructors' characteristics and attitudes toward older adults' participation in exercise. Results: For mostly seated classes, EXTEND qualification ( $B=0.36, p=.005)$ had a positive effect on instructors' attitudes. Later Life Training qualification $(B=-2.80, p=.003)$, clinical background $(B=-3.99, p=$ $.005)$, and delivering classes in National Health Services $(B=-3.12, p<.001)$, leisure centers $(B=-2.75, p=.002)$, or nursing homes $(B=-2.29, p=.005)$ had a negative effect on attitudes. For mostly standing classes, experience $(B=0.20$, $p=.003)$ and delivering in leisure centers $(B=0.46, p=.032)$ had a positive and clinical background $(B=-1.78, p=.018)$ had a negative effect on instructors' attitudes. Conclusions: Most instructors have positive attitudes, but training and work context can influence attitudes toward older people's participation in exercise classes both positively and negatively.
\end{abstract}

Keywords: theory of planned behavior, Later Life, exercise leaders

Encouraging older adults to become more active and maintain that activity is critical to promoting their health and well-being, social networks, and independence. In later life exercise brings physiological and psychological benefits and is associated with reduced illness, improved functional ability, and improved well-being, as well as preventing falls (Baker, Atlantis, \& Fiatarone Singh, 2007; Bean, Vora, \& Frontera, 2004; Stead, Wimbush, Eadie, \& Teer, 1997). However, in the United Kingdom, like many developed and some developing countries, inactivity increases with age (World Health Organization, 2002). Only 30\% of those age 65 or older report any regular exercise (Department of Health, 2010; Skelton, Young, Walker,

Hawley, Campbell, and Todd are with the School of Nursing, Midwifery and Social Work, University of Manchester, Manchester, UK. Skelton is with the School of Health and Social Care, Glasgow Caledonian University, Glasgow, UK. 
\& Hoinville, 1999). Strategies to improve motivation to both take up and adhere to exercise are important at any age, but perhaps more so in older people (Laventure \& Skelton, 2007). Engaging older adults in exercise is difficult. Physical deterioration with aging is often accepted by both older people themselves and health care professionals, and there is therefore reluctance to consider preventive measures (Sarkisian, Prohaska, Wong, Hirsch, \& Mangione, 2005; Stead et al., 1997). Even when older adults initiate exercise they often discontinue within 6 months (Jancey et al., 2007; Robison \& Rogers, 1994). If exercise, or increased activity, is to be beneficial it has to be maintained over time.

Factors that influence uptake and maintenance of exercise include individual factors, some of which are not open to manipulation, such as age, gender, ethnicity, and fall history, as well as factors open to change, such as individual's attitudes and beliefs about exercise (Lucidi, Grano, Barbaranelli, \& Violani, 2006; Yardley, Beyer, et al., 2007; Yardley, Donovan-Hall, Francis, \& Todd, 2007; Yardley et al., 2008). Attitudes and beliefs are themselves influenced by factors such as exercise history, perceptions of family and friends (Yardley, Donovan-Hall, et al., 2007), health status, and perception of one's ability to carry out the task (Finch, 1997; McAuley, 1993). The leadership behavior of instructors and quality of instruction and program are also important characteristics that can influence engagement in exercise (Dinan, 2001; Ecclestone \& Jones, 2004).

Previous studies have investigated the quality of individual instructors' delivery of exercise, although not necessarily with older adults (Fox, Rejeski, \& Gauvin, 2000). Leadership has been described as "the most important determinant of participation in physical activity groups" (Estabrooks et al., 2004, p. 233). Commitment to quality and involvement of exercise instructors have also been linked to participant satisfaction with participation and service provided (Loughead \& Carron, 2004). However, this has not yet been directly linked to maintenance of activity levels by older adults. Leadership has mostly been studied in relation to older adults through qualitative approaches; most focus on participants' perceptions of instructors (Chiang, Seman, Belza, \& Hsin-Chun Tsai, 2008; Estabrooks et al., 2004). Recent work reports that instructors' previous experience at leading a program can almost double adherence to attendance (Seguin et al., 2010). However, previous research has not specifically investigated how instructors' attitudes influence participants' adherence and attitudes to group exercise.

Intention to exercise and maintaining that exercise are influenced by individual participants' attitudes and perceptions. Previous work has used the theory of planned behavior (TPB; Ajzen, 1988) to explore how intention to exercise is predicted by perceived behavioral control (PBC), social influences, and attitudes, including perceived benefits and disadvantages of exercising (Downs \& Hausenblas, 2005; Lucidi et al., 2006; Yardley et al., 2006; Yardley, Donovan-Hall, et al., 2007). $\mathrm{PBC}$ is the perceived ease or difficulty of performing a behavior, reflecting past experiences, as well as perceived obstacles (Ajzen \& Driver, 1992). Social influence includes several constructs-subjective norms (beliefs of important people, e.g., family, professionals), perceived social support (support from others for the behavior), and modeling (following observed behavior of others). Attitudes concern the advantages and disadvantages of a particular behavior (outcome expectations) and when considered in relation to exercise maintenance can include how closely those outcome expectations are met. 
Recommendations from studies using TPB and other studies investigating older adults' uptake of and adherence to exercise suggest that professionals promote the benefits of exercise to older adults by encouraging the adoption of healthy, active lifestyles (particularly as a means of maintaining independence; British Heart Foundation, 2010; Hawley, 2009; Yardley et al., 2006; Yardley, Donovan-Hall, et al., 2007). Little is known about instructors' attitudes and how they promote their classes, even though this has the potential to influence participants' attitudes. It is clearly possible that if an instructor has negative beliefs about older adults' ability to participate in classes, does not believe that older adults can achieve positive outcomes through attending the class, or is not convinced of his or her own and others' (e.g., family, friends, and professionals) ability to encourage participation, this will negatively influence older adults' attitudes. In this article we report an observational study using TPB to explore exercise instructors' attitudes and what they are influenced by as a first step toward understanding how these attitudes may influence older adults' uptake and maintenance of exercise.

One way that instructors gain knowledge is through training. In the United Kingdom, in order for an exercise instructor to deliver classes to older adults paid for by the National Health Service (NHS), the instructor normally needs to possess a nationally recognized qualification in exercise-class provision at Level 3 or above (Register of Exercise Professionals [REPs], 2010a). This level of qualification permits an instructor to be described as an advanced instructor (REPs, 2010a). Level 3 training enables instructors to deliver to people with a mix of complex but stable conditions and disabilities (e.g., osteoporosis, coronary heart disease). Level 3 qualifications can be obtained via a number of training schemes (REPs, 2010b). Exercise instructors may initially complete Level 1 and 2 qualifications and deliver general exercise or physical fitness training before taking an older adult Level 3 qualification. There are also specialist older adult exercise-training companies that offer the choice of only taking a Level 3 older adult qualification permitting instructors only to deliver to older adults.

In the United Kingdom, the specialist older adult exercise-training companies and charities (EXTEND, 2010; Later Life Training [LLT], 2010) include considerable information on motivation of older adults to exercise, whereas other training providers (e.g., YMCAfit, 2010) do not specifically cover this. It is therefore likely that some training fosters more positive attitudes toward older adults than others. LLT's and EXTEND's sole focus is to provide specialist exercise training for people working with vulnerable older populations or people with health problems or disabilities. The qualifications these companies provide can be obtained without any previous background in the leisure and fitness industry, whereas most other training providers offer a range of qualifications for the leisure industry. Thus, those who obtain qualifications from either EXTEND or LLT are likely to have different backgrounds and deliver in different settings than those who obtain qualifications from the other training providers. It would seem logical that these instructors are likely to have different attitudes from those who received training from other sources.

Experience of instruction, professional background, where classes are offered, age, and gender are characteristics likely to influence instructors' attitudes. Although there has been little research in this area, qualitative research with older adults suggests that these are important attributes of a leader (Chiang et al., 2008; Estabrooks et al., 2004, Fox, Stathi, McKenna, \& Davis, 2007). One recent study found that 
exercise leader experience was related to adherence in older women (Seguin et al., 2010). The aim of the current study was to explore, using a UK-wide survey, the relationship between training and characteristics of instructors and their attitudes toward older adults' participation in exercise classes.

\section{Method}

\section{Participants}

Participants were recruited between March and July 2009 by approaching all instructors in the United Kingdom with a Level 3 or above older adult qualification. REPs is the regulatory body for exercise professionals in the United Kingdom, and we arranged for them to contact everyone on the national register with a Level 3 or above older adult qualification (REPs, 2010a). Although feedback from both REPs and training providers indicates that most instructors register with REPs, this is currently not mandatory. Therefore instructors were also approached through the two main organizations where REPs insurance is not required for delivery, to ensure wide representation of instructors. EXTEND and LTT are the largest training providers for Level 3 older adult qualifications. Both of these organizations agreed to help us contact Level 3 exercise instructors registered with them.

We used an Internet-based questionnaire and an identical postal questionnaire for those who did not have access to the Internet or preferred not to complete the questionnaire online. All data completed online and on paper could be provided anonymously. However, some respondents provided contact details, which were stored separately and password protected on a secure server. Because of UK dataprotection legislation and research-governance regulations, the research team was not allowed access to the actual databases of names and addresses of instructors. The three organizations helping us sent out all information and follow-ups, and it was not possible for us to identify nonrespondents to send out reminders to them. However, based on information provided by REPs and the training providers, we estimate that at the time of the survey there were some 3,000 older adult instructors with a valid Level 3 qualification in the United Kingdom. A sample-size calculation was not undertaken, because we attempted to survey the entire eligible population of Level 3 instructors.

\section{Measures}

The instructor questionnaire collected information about demography, professional background, experience, and qualifications. Because some training programs offer separate motivational training (e.g., the LLT course "Motivate Me") or continued professional development focusing on motivation, we collected this information, as well. For instructors currently delivering classes, descriptive information about the classes (e.g., where delivered) and instructors' attitudes toward older adults' participation in exercise classes was collected. Instructors were asked about their attitudes in relation to mostly seated and mostly standing classes, completing both sets of questions if they delivered both types of classes. This permitted investigation of the types of classes delivered and whether training and instructor characteristics influenced attitudes differently depending on the type of class. Some instructor- 
training companies such as EXTEND expect instructors to deliver classes with a seated element. Other companies such as the YMCA teach instructors to deliver more traditional standing aerobics or dance. Therefore, someone with a YMCA qualification is unlikely to deliver mostly seated classes and someone with only an EXTEND qualification will deliver mostly seated classes. Some instructors have received more than one type of training and therefore may deliver both types of classes. As a result, instructors may have differing attitudes with regard to older adults' participation, related to the type of class they deliver and the clientele they attract. It is important to note that the type of people attending different classes may not be determined by age but by the conditions the person has. Mostly seated classes are aimed at a less active audience, who are more likely to have a range of health problems than those attending mostly standing classes. Mostly standing classes were defined as those that were fully standing or spent $\leq 25 \%$ of the time seated. Classes in which $>25 \%$ of the time was spent seated were classed as mostly seated. The split between mostly seated and mostly standing was agreed on through discussion with those with experience in this field and because the different training qualifications lead to instructors' delivering different kinds of class.

For attitudes, an amended version of the TPB-based 6-item Attitudes to FallsRelated Interventions Scale (AFRIS; Yardley \& Todd, 2008) was administered. The original AFRIS was written to establish older adults' attitudes and beliefs about an intervention. Because we were using the AFRIS to ask instructors about their attitudes about older adults, the scale anchors were changed and additional questions were added based on work carried out by Yardley et al. (Todd et al., 2009). Our modified AFRIS comprised 13 items. After discussions with exercise professionals, we used 6-point Likert type scales (strongly agree to strongly disagree) to force respondents to express an opinion. Comments boxes were provided to permit participants to articulate issues about answering questions. Additional questions were asked as part of the social-influences scale to reflect current evidence about the instructors' influence (Chiang et al., 2008; Estabrooks et al., 2004; Fox et al., 2007) and to ascertain whether instructors believed that their support made a difference during classes and outside of the class. Rather than providing an overall attitude score as the original AFRIS does, this amended tool has separate scales for the different constructs to permit understanding of instructors' attitudes. This was deemed important because of the exploratory nature of the study. From the study data, the whole attitude scale has a Cronbach's $\alpha=.79$ for responses for those delivering mostly seated classes and $\alpha=.81$ for mostly standing classes, indicating good internal reliability for the attitude scales (Cronbach, 1951).

Instructors' attribution of older persons' PBC (attributed PBC) was measured using a single question in each section about whether the instructor thought an older adult would find it easy to participate in a mostly seated or mostly standing exercise class. Social influence was measured using three questions that asked whether the instructors thought that encouragement from other people (friends, family, and health professionals) whose opinions matter makes a difference to older adults' participation in a mostly seated or mostly standing exercise class. Another question asked instructors whether they felt that the support given to participants by an instructor during a mostly seated or mostly standing class can make a difference. The social-influences subscale had $\mathrm{a}=.58$ for mostly seated and $\mathrm{a}=.55$ for mostly standing. Although this is perhaps low, it is acceptable, because the 
scale measures slightly different concepts-social norms (influence of opinions of others) and social support.

Finally, beliefs about perceived positive or negative outcomes were measured using nine questions including items such as "attending a mostly seated/standing exercise class would be good for an older adult" and "doing a mostly seated/standing exercise class could cause an older adult to harm themselves." The subscale on beliefs about perceived outcomes had $\mathrm{a}=.74$ for mostly seated and $\mathrm{a}=.79$ for mostly standing.

\section{Analysis}

Data were analyzed using SPSS Release 15.0 (SPSS, Inc., 2006). Instructor age, gender, working background, training (including additional motivational training), place of delivery, and experience (months of delivery) were considered theoretically important in a model to predict instructors' attitudes. Ethnicity was excluded from the model because $90.3 \%$ (660/731) reported being White British. The remaining participants were from a range of different ethnic backgrounds, and were too few to permit meaningful analysis. Multiple regression was used to determine which variables predict each of the three attitude measures (total scores for attributed PBC, social influences, and beliefs about perceived outcomes) for instructors delivering mostly seated and those delivering mostly standing classes. Predictors were initially considered for multiple-regression modeling if they showed an individual association with an outcome at a conservative level of significance $(p \leq .25$; Hosmer \& Lemeshow, 2000). Thus, variables that could be important were not removed from the regression too early. The variables selected were then entered into exploratory regression models with backward selection used to remove variables one at a time. Backward selection is less likely to avoid excluding variables involved in suppressor effects and has a lower risk of missing good predictors (Field, 2009). The underlying assumptions of the final regression models were assessed and found to be broadly satisfactory. There was evidence of heterogeneity of variance in two of the six models (mostly seated social influences and mostly standing perceived outcomes); the pattern of results was not affected after transformation, so untransformed results are presented for ease of comparison.

\section{Results}

In total, 776 instructors returned questionnaires; 45 were excluded because they did not report having Level 3 qualification. Of the 731 eligible responders, 200 completed paper questionnaires and 531 completed the online version. In recruiting 731 instructors, we estimate that approximately a quarter of instructors trained and a third of instructors actively delivering with Level 3 qualification participated. Most respondents (91\%) were women. Respondents' mean age was 51.5 years (SD 13.2); age ranged from 20 to 94 . Some 635 (88\%) were currently delivering classes with participants over the age of 60 . The instructors' background, experience, ethnicity, and type of class delivered are reported in Table 1. Most responders had undergone LLT, EXTEND, or YMCA training (Table 1). Others had undertaken a variety of other older adult qualifications awarded by companies providing a range of exercise qualifications. Most instructors had generally positive attitudes 


\section{Table 1 Characteristics of Participating Instructors of Older Adults}

\begin{tabular}{lc}
\hline Characteristic & $\boldsymbol{n}(\%)$ \\
\hline Gender & $63(9 \%)$ \\
male & $668(91 \%)$ \\
female & \\
Ethnicity & $660(90 \%)$ \\
White British & $71(10 \%)$ \\
other & \\
Background & $301(41 \%)$ \\
fitness and sports & $197(27 \%)$ \\
National Health Service clinical & $64(9 \%)$ \\
social care & $61(8 \%)$ \\
community/voluntary & $27(4 \%)$ \\
education & $64(9 \%)$ \\
other & $17(2 \%)$ \\
missing & \\
Training & $40(6 \%)$ \\
YMCA only & $333(46 \%)$ \\
EXTEND only & $229(31 \%)$ \\
Later Life Training only & $36(5 \%)$ \\
Later Life Training and EXTEND & $23(3 \%)$ \\
Later Life Training and YMCA & $70(10 \%)$ \\
other Level 3 older adult classification & \\
Type of exercise class delivered & $96(13 \%)$ \\
not currently delivering & $378(52 \%)$ \\
mostly seated & $269(37 \%)$ \\
mostly standingb & $109(15 \%)$ \\
missing & $\mathbf{M ( S D ) , ~ M e d i a n ~ ( r a n g e ) ~}$ \\
\cline { 2 - 2 } Attitudes to Falls-Related Interventions Scale, mostly seated & \\
attributed perceived behavioral control & $5.1(0.9), 5.0(2-6)$ \\
social influences & $16(1.6), 16(8-18)$ \\
beliefs about perceived outcomes & $43.3(5.1), 44.0(26-54)$ \\
Attitudes to Falls-Related Interventions Scale, mostly standing & \\
attributed perceived behavioral control & $4.3(1.0), 4.0(1-6)$ \\
social influences & $(1.66), 16(9-18)$ \\
beliefs about perceived outcomes & $5.2), 45.0(25-54)$ \\
\hline
\end{tabular}

aTotal number of instructors who provided data on delivery of mostly seated classes (including those who deliver both). ${ }^{b}$ As above for mostly standing classes. ${ }^{\mathrm{c}}$ Those who said they delivered classes but did not complete information about them. 
(Table 1). There were significant differences in age between those who completed the questionnaire on paper and those who completed it online ( $M 61.1$ vs. 47.8 years, $t=-14.42, d f=414.35, p<.001)$. There were also significant differences in experience between paper and online completion for both mostly seated ( $M 54.8$ vs. 68.8 months, $Z=-3.08, p=.002$ ) and mostly standing classes ( $M 143.3$ vs. 99.6 months, $Z=-1.94, p=.053$ ). Paper questionnaires were only sent routinely to EXTEND instructors (who were expected to be older than other instructors). The only significant difference found in attitudes between those who completed the questionnaire online and those who completed it on paper was for attributed PBC for those who delivered mostly standing classes ( $M 4.2$ vs. $4.7, t=2.77, d f$ $=262, p=.006$ ), with those who completed paper questionnaires having higher attributed-PBC scores. However, this is likely to be a result of factors such as age and experience of the instructor (as reflected in the regression models).

In testing the differences between those who delivered only mostly seated and only mostly standing classes, we found that there were significant differences for attributed PBC (mostly seated $M=5.1$ vs. mostly standing $M=4.2, t=-8.87, d f$ $=394, p<.001)$. We also tested within-group differences for those who delivered and answered both sets of attitudes questions: There were statistically significant differences for attributed PBC (mostly seated $M 4.9$ vs. mostly standing $M 4.3, t=$ $5.43, d f=116, p<.001)$ and beliefs about perceived outcomes $(M 42.4$ vs. 44.1, $t$ $=-3.28, d f=117, p=.001)$.

\section{Mostly Seated Classes}

For mostly seated classes, backward regression revealed that instructors who had undertaken EXTEND training had significantly higher (more positive) attitude scores than those who had not for attributed PBC $(p=.005$; Table 2). Compared with those delivering in other settings, instructors who delivered classes in NHS settings $(p=.038)$ had significantly lower scores, and those who delivered in nursing homes had almost significantly $(p=.055)$ lower scores, for attributed PBC (Table $2)$. Instructors who delivered in NHS settings $(p=.005)$ also had significantly lower social-influences scores than those who delivered in other settings.

Instructors who came from other backgrounds (including administrative, management, and health promotion) had more positive beliefs about perceived outcomes than those from community/voluntary, education, social care, or NHS clinical backgrounds $(p=.017)$. Women had more negative beliefs about perceived outcomes than men $(p=.026)$, as did those with LLT training compared with those without LLT training $(p=.003)$.

Compared with those delivering in other venues, instructors who delivered in NHS settings $(p<.001)$, leisure centers, gyms $(p=.002)$, or nursing homes $(p=$ $.005)$ had more negative beliefs about perceived outcomes.

Overall, however, the $p$ values should be interpreted with caution because backward selection of variables is exploratory and the sample size was large. The amounts of variance explained by the three multiple-regression models are adjusted $R^{2}=.06$ for attributed PBC, adjusted $R^{2}=.03$ for social influences, and adjusted $R^{2}=.16$ for beliefs about perceived outcomes. When interpreting $R^{2}$ for regression, one should consider .02 a small, .13 a medium, and .26 a large effect size (Cohen, 1992). 


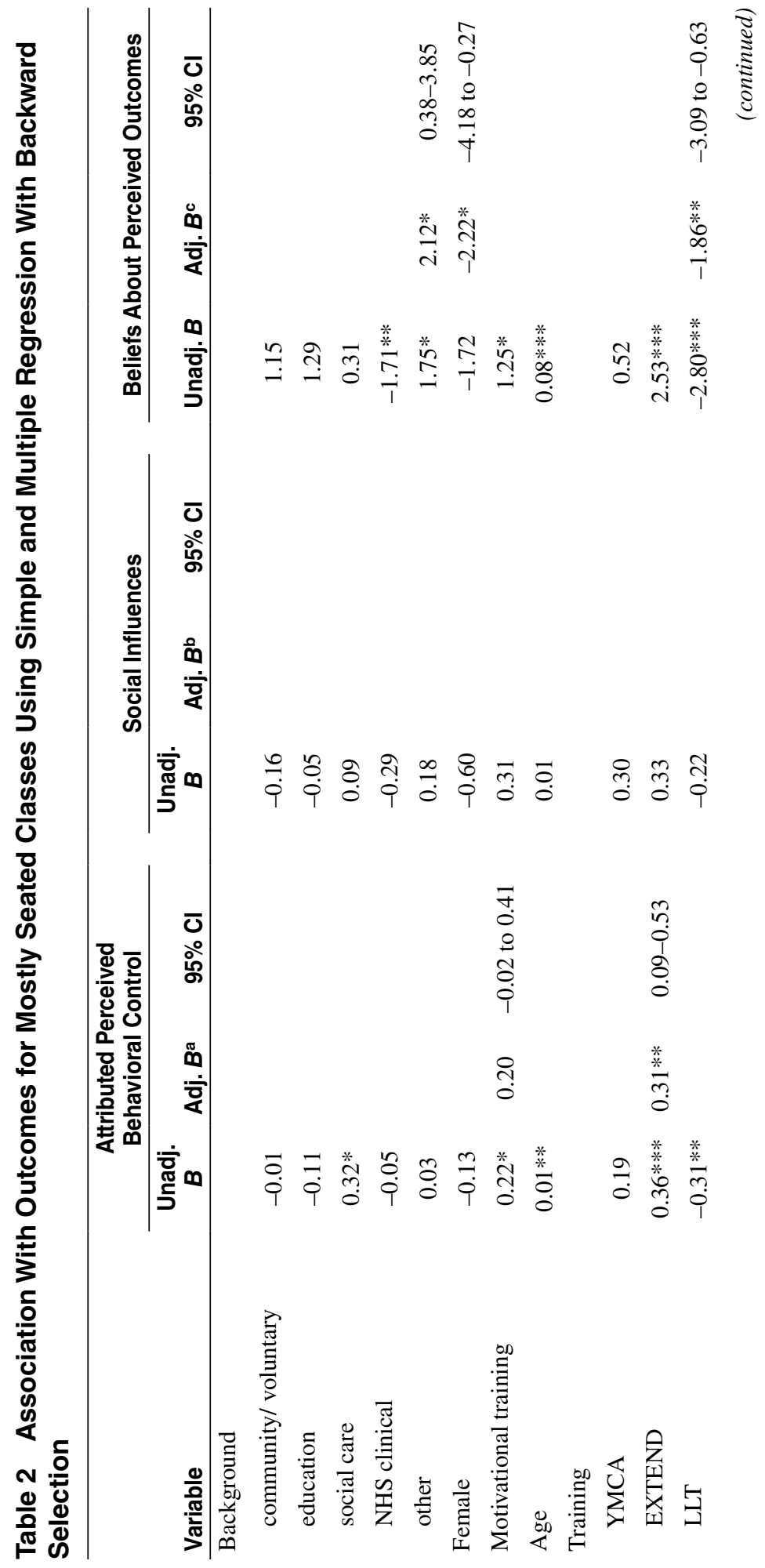




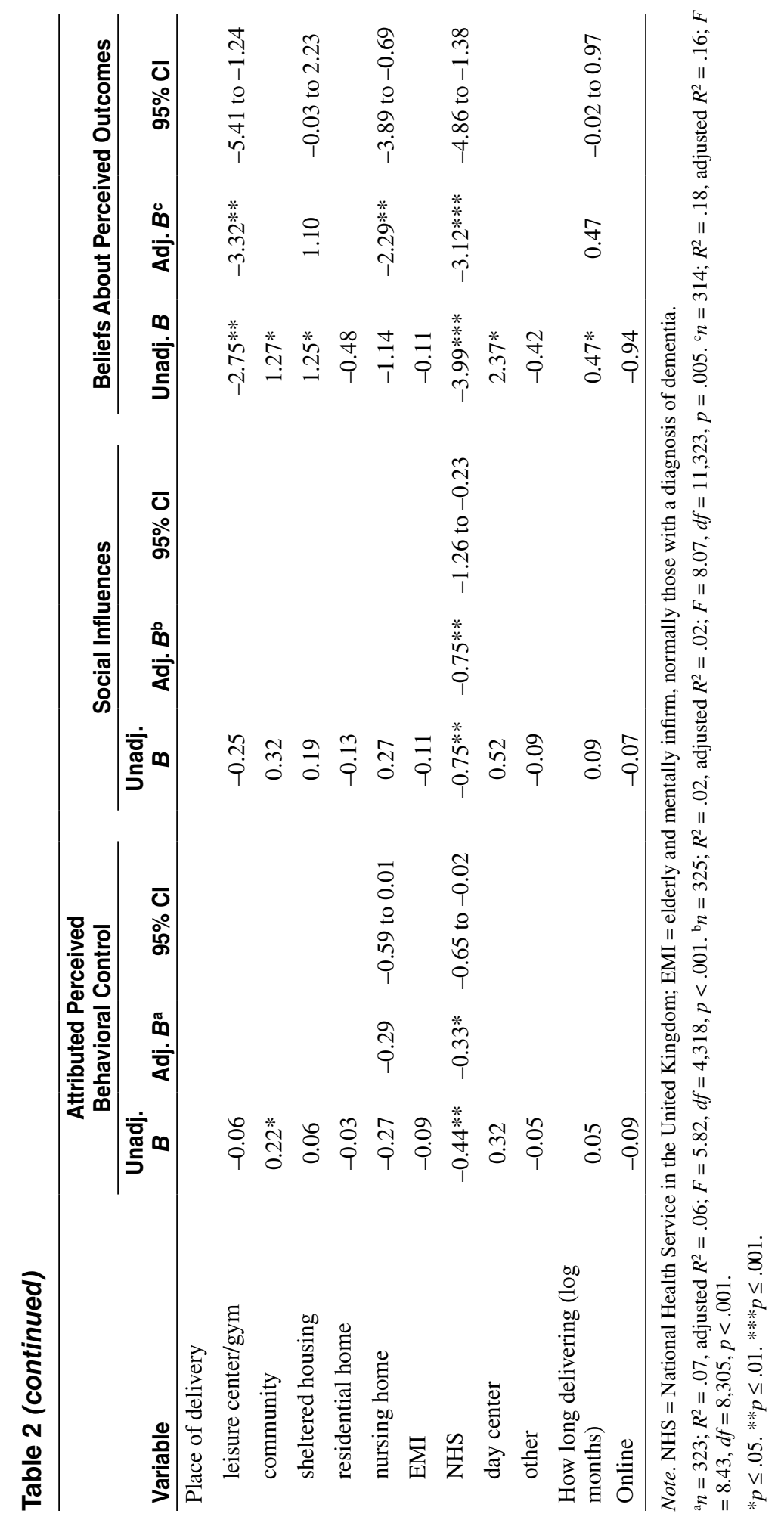




\section{Mostly Standing Classes}

For mostly standing classes (Table 3), instructors' experience (based on months delivered; $p=.003$ ) was significantly related to a more positive attributed-PBC score, whereas having undertaken LLT $(p=.001)$ or YMCA $(p=.037)$ training was related to a more negative attributed PBC than having undertaken neither. Undertaking LLT training $(p<.001)$ and delivering in a leisure center or gym $(p$ $=.032$ ) had a positive effect on social influences compared with other locations of delivery (Table 3). Those from an NHS clinical background had more negative beliefs about perceived outcomes than those from other backgrounds $(p=.018)$. The amounts of variance explained are adjusted $R^{2}=.10$ for attributed PBC, adjusted $R^{2}=.01$ for social influences, and adjusted $R^{2}=.04$ for beliefs about perceived outcomes.

\section{Discussion}

This study looked at whether instructors' training and characteristics influence their attitudes toward older adults' participation in classes. A UK national survey was used to establish broad representation of instructors. Most instructors' scores indicated positive beliefs about older adults' participation in exercise classes. Because of the number of explanatory variables, the regression analyses should be considered exploratory (i.e., hypothesis generating rather than hypothesis demonstrating).

Very few quantitative studies have been conducted specifically looking at the role of the instructor. Seguin et al. (2010) found that previous experience of the instructor was related to adherence levels to the class. We found that instructors who delivered mostly standing classes and who had been delivering classes for longer had more positive attitudes, which possibly explains the increased adherence levels found by Seguin et al.

Instructors who express beliefs that older adults can participate in exercise classes and will achieve positive outcomes through attending and also think that they and others have a role to play in encouraging older adults to participate in classes could have the potential to influence older adults' attitudes. These factors are from the TPB and have been identified in previous research (Lucidi et al., 2006; Yardley, Donovan-Hall, et al., 2007; Yardley et al., 2006) as influencing both older adults' intention to and their maintenance of exercise. Those who delivered mostly seated classes and had undertaken EXTEND training demonstrated some of these positive attitudes. One might hypothesize that instructors' positive attitudes about older adults' abilities to participate, as well as their understanding of their own potential influence, are underlying factors explaining previously found levels of older adults' attendance and adherence (Chiang et al., 2008; Estabrooks et al., 2004; Fox et al., 2007). This is supported by qualitative comments in the open comments section of the questionnaire. For example, one instructor wrote that an important attribute was "being sensitive to their limitations and an awareness that they are really trying hard and should be praised accordingly." EXTEND instructors are trained to adapt to participants' limitations and to believe that all older adults, even ones with limitations, can participate.

Qualitative studies reveal that health professionals influence older adults' attitudes to exercise (Hawley, 2009; Horne, Skelton, Speed, \& Todd, 2009). The 


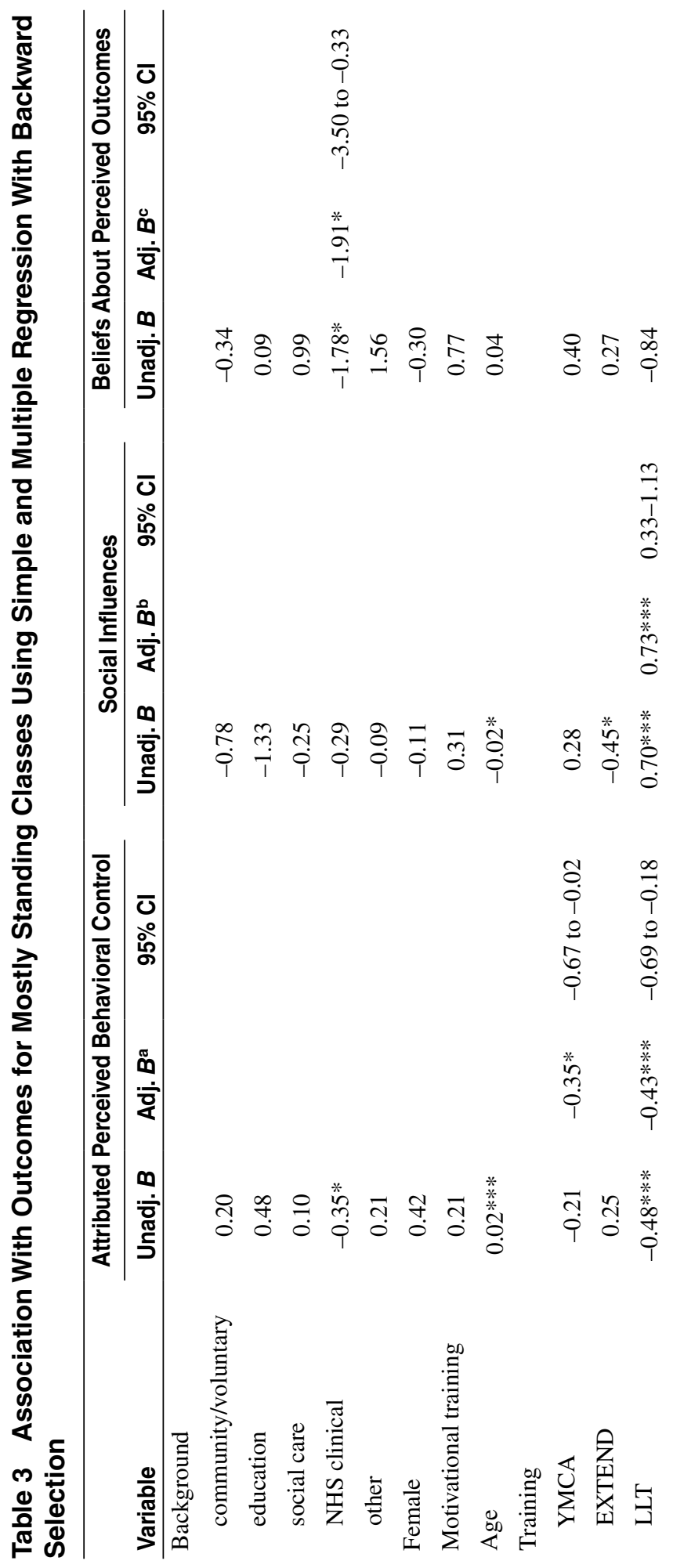




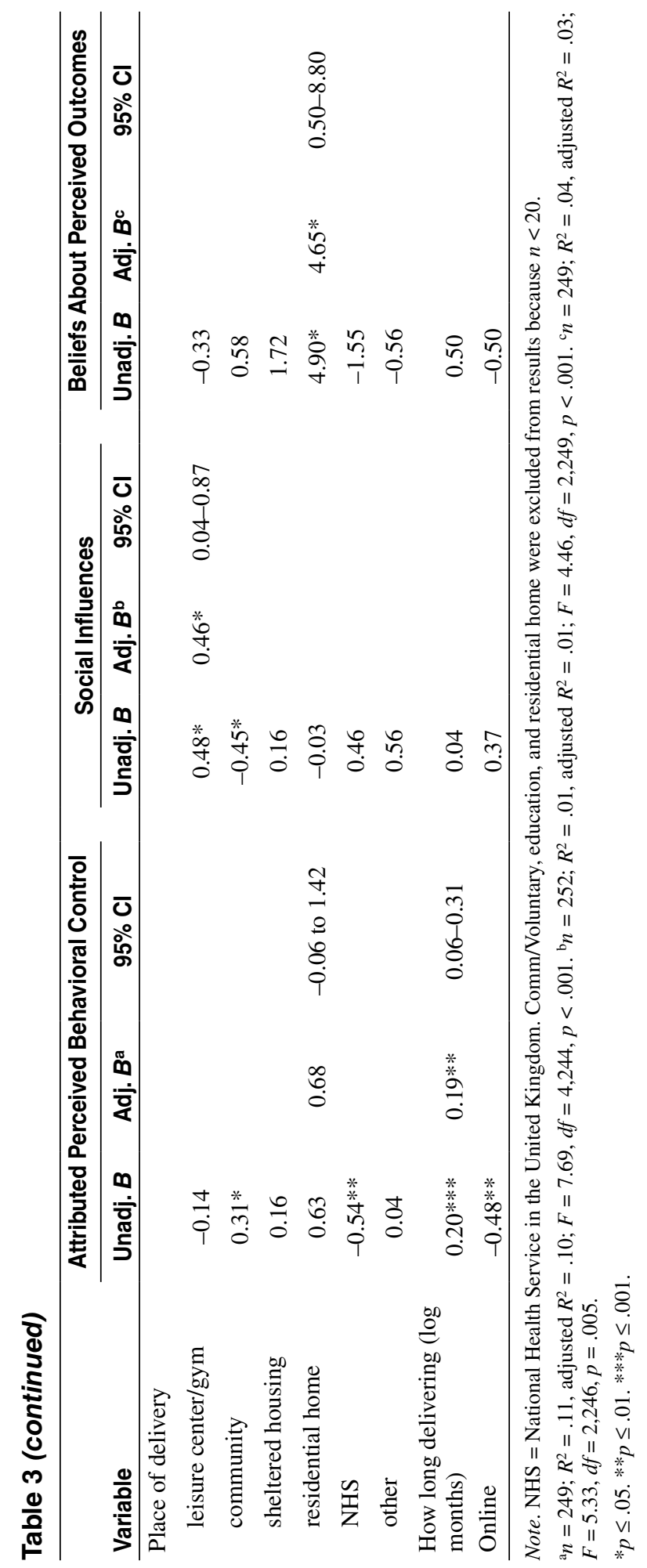


current study finds that for instructors who deliver mostly standing classes, an NHS clinical background had a negative effect on beliefs about outcomes that older adults could achieve. Delivering in an NHS setting also had a negative effect on attributed PBC, social influences, and beliefs about outcomes for those who delivered mostly seated classes. Delivery in NHS rehabilitation settings imposes limitations on the effect of exercise, because the usual length of NHS-funded classes is 6-8 weeks. Clinicians may have more positive and supportive attitudes about older adults' participation in exercise classes delivered in the community and also home exercise, because these are delivered for longer and in a person's own environment. This is not reflected herein but has been found in older adults' qualitative accounts of the support they receive from their health professionals (Hawley, 2009; Horne et al., 2009) to exercise at home and in the community.

Instructors who had undertaken LLT training and those who delivered in gym or leisure-center settings had less positive views about mostly seated classes. It is possible that this is either because their participants are more active older adults who do not require a mostly seated class (gym/leisure center) or because there is a focus on improving balance, which requires participants to stand (LLT). For example, one instructor who was LLT trained wrote, "I think mostly seated exercise groups are good to introduce patients into exercise, but for real balance and independence gains progression to mostly standing is required." This requires further exploration, however. There are also differences in attitudes depending on the setting (e.g., care homes, sheltered housing) and the gender of the instructor that also require further exploration.

Future qualitative work is required to explore instructors' attitudes and beliefs and what other factors influence these. Future quantitative studies are required to further understand how instructors' attitudes may influence participants. The current study was exploratory so it is difficult to make firm recommendations. However, we have established that instructors with more experience who deliver mostly standing classes are more likely to have positive attitudes (attributed PBC) toward older people's participation. Previous research has revealed that previous experience relates to adherence. Therefore, we suggest that when new classes are started (before behavior is established), the use of an experienced instructor may help promote adherence levels of older adults. Training that encourages instructors to have positive attitudes about the support and motivation they provide to older adults may also enhance older adults' experience of exercise classes.

\section{Limitations}

There are various limitations to the study. Instructors' attitudes had not previously been examined, so this survey was exploratory. Participants may have self-selected into the survey because we were unable to target nonresponders for follow-up. Thus, it is possible that only the most enthusiastic instructors responded, which could introduce bias. However, there were responses from instructors who were not currently delivering, which suggests that we actually accessed the population quite widely. Although the attitude questions were based on an existing tool, this had only previously been used with older adults and had to be adapted for use with instructors. Instructors said they found it difficult to generalize, as evidenced by 
the comments to the open questions, and further investigation is required using qualitative methods. There could also be subtle differences between qualifications that were combined under "other" Level 3 older adult qualification. Qualitative methods will permit these to be explored in the future.

Our definition of mostly seated classes was quite broad and could create withincategory variance. This definition captures classes in which participants are seated for $50 \%$ or even $100 \%$ of the time. However, this was chosen because of differences observed between classes where participants were only seated for $25 \%$ of the time (often only for the strength exercises) and classes where participants were seated for longer.

Our study design does not permit us to establish whether the differences in instructors' attitudes between mostly seated and mostly standing classes reflect the training they have undertaken, abilities of participants who attend their classes, a combination of both, or other potentially causal factors. Some instructors had more than one type of qualification, delivered both types of classes, and had differing attitudes to mostly seated and mostly standing classes.

It is possible that LLT and YMCA training were negatively associated with attributed PBC for mostly standing classes because of the wording of the PBC question, which asked whether an older adult would find it easy to participate. Those who have attended either of these training programs are unlikely to perceive these classes as easy, because they are designed for quite active older adults (YMCA) and to challenge participants' strength and balance (LLT). This needs to be further explored. Finally, small to medium values of adjusted $R^{2}$ suggest that most of the variance of the dependent variables was left unexplained, so other factors that might influence instructors' attitudes need to be considered.

\section{Conclusion}

In overview, it is clear that there are important relationships between background variables such as experience and training received by instructors (and thus the sort of exercise class provided) and attitudes. Further research is required to fully understand how instructors' attitudes are formed and how they can be influenced. The regression models fitted in this study only explain small amounts of variance, and other factors such as personality may be more influential. Further research is required to investigate whether instructors' attitudes influence older adults' attitudes. This is important because unless older adults have positive attitudes toward exercise they are unlikely to adhere to regimens that provide health benefits.

\section{Acknowledgments}

Conflict of interest: Dawn Skelton is a director of Later Life Training and was a trustee of EXTEND for 12 years. She is also involved in the delivery of motivation training. Helen Hawley, as part of her NHS employment, has worked with a variety of training providers including EXTEND, Later Life Training, and providers who deliver other Level 3 qualifications.

This study was funded through a Strategic PhD Studentship funded by the Medical Research Council and the University of Manchester. 


\section{References}

Ajzen, I. (1988). Attitudes, personality and behaviour. Maidenhead, UK: Open University Press.

Ajzen, I., \& Driver, B.L. (1992). Application of the theory of planned behaviour to leisure choice. Journal of Leisure Research, 24, 204-224.

Baker, M.K., Atlantis, E., \& Fiatarone Singh, M.A. (2007). Multi-modal exercise programs for older adults. Age and Ageing, 36, 375-381 .

Bean, J.F., Vora, A., \& Frontera, W.R. (2004). Benefits of exercise for community-dwelling older adults. Archives of Physical Medicine and Rehabilitation, 85, S31-S42.

British Heart Foundation. (2010). Active for Later Life resource. London: Author. Available at http://www.webcitation.org/5q3vuILSF

Chiang, K., Seman, L., Belza, B., \& Hsin-Chun Tsai, J. (2008). "It is our exercise family": Experiences of ethnic older adults in a group-based exercise program. Preventing Chronic Disease, 5, A05-A05.

Cohen, J. (1992). A power primer. Psychological Bulletin, 112, 155-159.

Cronbach, L.J. (1951). Coefficient alpha and the internal structure of tests. Psychometrika, 16, 297-333.

Department of Health. (2010). On the state of public health: Annual report of the chief medical officer (pp. 21-28). London: Her Majesty's Stationary Office.

Dinan, S. (2001). Delivering an exercise prescription for vulnerable older patients. In A. Young \& M. Harries (Eds.), Physical activity for patients. An exercise prescription (pp. 121-132). London: Royal College of Physicians.

Downs, D., \& Hausenblas, H. (2005). Elicitation studies and the theory of planned behavior: A systematic review of exercise beliefs. Psychology of Sport and Exercise, 6, 1-31 .

Ecclestone, N.A., \& Jones, J. (2004). International curriculum guidelines for preparing physical activity instructors of older adults, in collaboration with the Aging and Life Course, World Health Organization. Journal of Aging and Physical Activity, 12, 467-479.

Estabrooks, P.A., Munroe, K.J., Fox, E.H., Gyurcsik, N.C., Hill, J.L., Lyon, R.L., . . . Shannon, V.R. (2004). Leadership in physical activity groups for older adults: A qualitative analysis. Journal of Aging and Physical Activity, 12, 232-242.

EXTEND. (2010). Maintain an independent active lifestyle through exercise. Available at http://www.webcitation.org/5pHfFU4PE

Field, A. (2009). Discovering statistics using SPSS (3rd ed.). London: Sage.

Finch, H. (1997). Physical activity at our age: Qualitative research among people over the age of 50. London: Health Education Authority.

Fox, L.D., Rejeski, J., \& Gauvin, L. (2000). Effects of leadership style and group dynamics on enjoyment of physical activity. American Journal of Health Promotion, 14, 277-283.

Fox, L.D., Stathi, A., McKenna, J., \& Davis, M.G. (2007). Physical activity and mental wellbeing in older people participating in the Better Ageing Project. European Journal of Applied Philosophy., 100, 591-602.

Hawley, H. (2009). Older adults' perspectives on home exercise after falls rehabilitation-An exploratory study. Health Education Journal, 68, 207-218 .

Horne, M., Skelton, D., Speed, S., \& Todd, C. (2009). The influence of primary health care professionals in encouraging exercise and physical activity uptake among White and South Asian older adults: Experiences of young older adults. Patient Education \& Counseling, 78(1), 97-103.

Hosmer, D.W., \& Lemeshow, S. (2000). Applied logistic regression (2nd ed.). New York: John Wiley.

Jancey, J., Lee, A., Howat, P., Clarke, A., Wang, K., \& Shilton, T. (2007). Reducing attrition in physical activity programs for older adults. Journal of Aging and Physical Activity, 15, 152-165. 
Later Life Training. (2010). Later Life Training Web page. Retrieved from http://www. laterlifetraining.co.uk.

Laventure, R., \& Skelton, D.A. (2007). Breaking down the barriers: Strategies to motivate the older client to begin and sustain exercise participation. Fitness Professionals., 9, $42-43$.

Loughead, T.M., \& Carron, A.V. (2004). The mediating role of cohesion in the leader behaviour-satisfaction relationship. Psychology of Sport and Exercise, 5, 355-371.

Lucidi, F., Grano, C., Barbaranelli, C., \& Violani, C. (2006). Social-cognitive determinants of physical activity attendance in older adults. Journal of Aging and Physical Activity, 14, 344-359.

McAuley, E. (1993). Self-efficacy and the maintenance of exercise participation in older adults. Journal of Behavioral Medicine, 16, 103-113 .

Register of Exercise Professionals. (2010a). New structure for REPS. Retrieved from http:// www.exerciseregister.org/REPsQualsFramework2010.html

Register of Exercise Professionals. (2010b). Qualifications \& training portal. Available at http://www.webcitation.org/5pHgEFFFJ

Robison, J.L., \& Rogers, M.A. (1994). Adherence to exercise programs: Recommendations. Sports Medicine (Auckland, N.Z.), 17, 39-52.

Sarkisian, C.A., Prohaska, T.R., Wong, M.D., Hirsch, S., \& Mangione, C.M. (2005). The relationship between expectations for aging and physical activity among older adults. Journal of General Internal Medicine, 20, 911-915.

Seguin, R.A., Economos, C.D., Palomobo, R., Hyatt, R., Kuder, J., \& Nelson, M.E. (2010). Strength training and older women: A cross sectional study examining factors related to exercise adherence. Journal of Aging and Physical Activity, 18, 201-218.

Skelton, D.A., Young, A., Walker, A., \& Hoinville, E. (1999). Physical activity in later life: Further analysis of the Allied Dunbar national fitness survey and the Health Education Authority survey of activity and health. London: Health Education Authority.

SPSS Inc. (2006). SPSS statistical software Release 15. Chicago, IL: Author.

Stead, M., Wimbush, E., Eadie, D., \& Teer, P.A. (1997). A qualitative study of older people's perceptions of ageing and exercise: The implications for health promotion. Health Education Journal, 56, 3-16.

Todd, C., Whitehead, S., Yardley, L., Kirby, S., Ben-Shlomo, Y., \& Gilbert, R. (2009). Falls and fall prevention amongst older people: Socio-economic and ethnic factors. Manchester, UK: University of Manchester.

World Health Organization. (2002). Active ageing: A policy Framework. Available at www. whqlibdoc.who.int/hq/2002/WHO_NMH_NPH_02.8.pdf

Yardley, L., Beyer, N., Hauer, K., McKee, K., Ballinger, C., \& Todd, C. (2007a). Recommendations for promoting the engagement of older people in activities to prevent falls. Quality and Safety in Health Care, 16, 230-234.

Yardley, L., Bishop, F., Beyer, N., Hauer, K., Kempen, G.I., Piot-Ziegler, C., . . Holt, A.R. (2006). Older people's views of falls-prevention interventions in six European countries. The Gerontologist, 46, 650-660.

Yardley, L., Donovan-Hall, M., Francis, C., \& Todd, C. (2007b). Attitudes and beliefs that predict older people's intention to undertake strength and balance training. Journal of Gerontology: Psychological Sciences, 2, 199-225.

Yardley, L., Kirby, S., Ben-Shlomo, Y., Gilbert, R., Whitehead, S., \& Todd, C. (2008). How likely are older people to take up different falls prevention activities? Preventive Medicine, 47, 554-558.

Yardley, L., \& Todd, C. (2008). Attitudes to Falls-Related Interventions Scale (AFRIS). Available at http://www.webcitation.org/5q3w3xPN8

YMCAfit. (2010). YMCAfit Web site. Retrieved from http://www.ymcafit.org.uk 